\title{
Pharmacogenomics of Cytochrome P450 Dependent Metabolism of Endogenous Compounds: Implications for Behavior, Psychopathology and Treatment
}

\author{
Anna Persson and Magnus Ingelman-Sundberg* \\ Section of Pharmacogenetics, Department of Physiology and Pharmacology, Karolinska Institutet, Stockholm, Sweden
}

\begin{abstract}
Mood and anxiety disorders are a major burden to the society today but still the pathophysiology behind these disorders is largely unknown and the pharmacotherapy available today is far from sufficient, with relatively low remission rates. Recent results regarding the action of CYP2C19 and CYP2D6 in the CNS suggest associations between suicidality, anxiety and other stress-related disorders and such CYP enzyme polymorphisms. Knowledge about the CNS specific action of these enzymes might in the future provide an increased understanding of the pathogenesis and pathophysiology of these disorders. Here we present an update of the research carried out in human and animal models with focus on the roles of CYP2C19 and CYP2D6 for brain development and function mediated by the metabolism of endogenous compounds.
\end{abstract}

Keywords: CYP2D6; CYP2C19; Psychopathology; Depression; Polymorphism; Suicidality; Anxiety

\section{Introduction}

The human genome carries 57 genes encoding active cytochrome P450 enzymes. About 6-8 of these genes encode P450 enzymes active in the metabolism of clinically used drugs [1,2]. A large majority of these genes are polymorphic and alleles causing defective, diminished, qualitatively altered or increased drug metabolism have been described (See The Human Cytochrome P450 (CYP) Allele Nomenclature Database; www.cypalleles.ki.se). This variation is of importance for explaining interindividual differences in drug metabolism, drug efficacy and adverse drug reactions. Because of the major function for metabolism of exogenous compounds in the hepatic detoxifications processes these polymorphisms do not cause any major alterations in the phenotype of the individual. Accordingly no major phenotype in KO mice for any cytochrome P450 gene encoding hepatic enzymes active in drug metabolism has been described, although phenotypic changes have been seen in transgenic mice overexpressing some Cyps. The endogenous role in metabolism of the P450s in question is mainly related to oxidation of cholesterol, bile acids, steroid hormones and fatty acids [1]. Thus in mice transgenic for CYP3A4, disturbances in lactation of female mice are seen due to increased estradiol metabolism [3]. The area of endogenous roles of the P450 polymorphism has however not been completely unraveled. Phenotypes not obvious might however be related to such polymorphisms and indeed many examples

\begin{tabular}{|l|c|c|}
\hline Substrates & CYP2C19 & CYP2D6 \\
\hline \multirow{3}{*}{ Exogenous } & Amitriptyline Clomipramine & Antiarrhythmics \\
& Citalopram & Antipsychotics \\
Biazepam Mephenytoin & Beta blockers \\
Moclobemide & Codeine \\
& Sertraline & Dextromethorphan \\
& SSRIs \\
\hline \multirow{2}{*}{ Endogenous } & Tricyclic antidepressants \\
\hline & Arachidonic acid & Anandamide \\
& Docosahexaenoic acid & 5-Methoxytryptamine Pregnenolone \\
& Eicosapentaenoic acid & Progesterone \\
& Estradiol & Serotonin \\
& Progesterone & Testosterone \\
& Testosterone & Tyramine \\
\hline
\end{tabular}

Table 1: Some CNS active substrates for CYP2C19 and CYP2D6. of associations between such genetic variation and altered endogenous functions and phenotypes have been presented in the literature. Specific interesting aspect concerns the endogenous roles of cytochrome P450s expressed in the brain [4]. We here present recent results obtained regarding the CNS specific functions of CYP2D6 and CYP2C19 and possible implications for CNS disease.

\section{CYP2D6}

CYP2D6 is highly polymorphic and in Caucasians $7-10 \%$ are defective for expression of this enzyme (PMs) whereas $2-10 \%$ carry more than one functionally active CYP2D6 gene on each allele and are ultra-rapid metabolizers (UMs) [5,6]. The enzyme has been suggested to be active in the metabolism of the endogenous compounds 5-methoxytryptamine, anandamide, progesterone and tyramine [4] (Table 1). CYP2D6 mRNA and protein has been found in neurons in numerous human brain areas, including e.g. thalamus, hypothalamus, hippocampus, substantia nigra, cerebellum, and in several layers of the frontal neocortex $[7,8]$. The fact that CYP2D6 is expressed in the brain raises questions regarding its potential functions within the brain and more specifically in the neurons. It is likely that regional expression of CYP2D6 affects local metabolism of CNS-acting drugs metabolized by the enzyme that in turn can affect treatment outcome. However, CYP2D6 has in the last decade also been suggested to be involved in endogenous metabolism of e.g. trace amines and neurosteroids, which implicates a role in normal brain homeostasis as well. Several studies have shown that CYP2D6 expressed in liver and brain can metabolize tryptamines into both serotonin and dopamine $[9,10]$, and furthermore

*Corresponding author: Magnus Ingelman-Sundberg, Section of Pharmacogenetics, Department of Physiology and Pharmacology, Karolinska Institutet, Nanna Svartz väg 2, SE- 17177 Stockholm, Sweden, Fax + 468-337 327; Tel: + 468-5248 7735; E-mail: Magnus.Ingelman-Sundberg@ki.se

Received March 19, 2014; Accepted April 03, 2014; Published April 10, 2014

Citation: Persson A, Ingelman-Sundberg M (2014) Pharmacogenomics of Cytochrome P450 Dependent Metabolism of Endogenous Compounds: Implications for Behavior, Psychopathology and Treatment. J Pharmacogenomics Pharmacoproteomics 5: 127. doi:10.4172/2153-0645.1000127

Copyright: (C) 2014 Persson A, et al. This is an open-access article distributed under the terms of the Creative Commons Attribution License, which permits unrestricted use, distribution, and reproduction in any medium, provided the original author and source are credited. 
Citation: Persson A, Ingelman-Sundberg M (2014) Pharmacogenomics of Cytochrome P450 Dependent Metabolism of Endogenous Compounds: Implications for Behavior, Psychopathology and Treatment. J Pharmacogenomics Pharmacoproteomics 5: 127. doi:10.4172/21530645.1000127

metabolize the neurosteroid progesterone [11,12]. Further supporting this hypothesis is the CYP2D6 transgenic mouse model, displaying brain expression of the enzyme, displaying significantly higher serotonin levels in several brain regions, including the cerebellum and hippocampus [13].

In vitro studies also suggest that CYP2D6 is involved in the transformation of other neurosteroids like testosterone [14] and pregenolone [15]. Additionally, CYP2D6 has also been suggested to be involved in the endocannabinoid system within the CNS due to its ability to metabolize anandamide and its derivatives [16]. The physiological significance of such metabolism is however still unclear and the affinities for CYP2D6 enzyme by the compounds suggested might in many cases not be appropriate for significant metabolism under physiological conditions.

\section{Psychopathology and behavior}

Associations between CYP2D6 genotypes and personality traits were one of the first indications that CYP2D6 might have endogenous functions apart from its important role in drug metabolism.In one of the first reports it was shown that poor metabolizers displayed higher impulsivity-related traits [17]. Further studies have found similar traits among poor metabolizers [18] whereas others have found poor metabolizers to be more anxiety-prone and less successful in socialization, when compared with extensive metabolizers $[19,20]$. The inconclusive results could be explained by the different ethnicities of the populations and methods used but do however suggest that CYP2D6 might have important endogenous functions in the human brain.

Furthermore, the ultra-rapid metabolizer phenotype where the subjects carry 3 or more active CYP2D6 genes has been associated with higher suicidal risk $[21,22]$ as well as increased suicidal behavior among individuals with eating disorders [23]. The number of active CYP2D6 genes has been associated with higher perfusion rates in the thalamus and the right hippocampus among healthy human subjects during resting [24] and lower perfusion rates in the cuneus and precuneus during cognitive tasks [25]. This provides an interesting mechanistic link to the findings concerning a relationship to suicidality, although as a whole these results have to be reproduced in larger independent cohorts before causality can be concluded.

Interestingly, an increased risk for Parkinson's disease among CYP2D6 poor metabolizers was recently described in a large metaanalysis [26]. Poor metabolizers furthermore displayed a better capacity to vigilance and alertness when exposed to a specific assignment and performed better in spatial memory tasks [27]. The displayed differences in neurocognitive function and perfusion rates display direct effects of CYP2D6 polymorphism on brain function. However, the basis for a CYP2D6 dependent influence on brain function remains unknown. CYP2D6 is very active in the metabolism of CNS active drugs, preferentially those containing basic nitrogens, so it might be suggested that the endogenous CYP2D6 substrates have similar structures and act as ligands to receptors within e.g. the serotonergic and dopaminergic systems.

\section{CYP2C19}

CYP2C19 is an important drug metabolizing enzyme involved in the metabolism of approximately $7-10 \%$ of all drugs used on the market today demonstrating broad substrate specificity $[2,28]$. The CYP2C19 gene, like many other CYP genes, is highly polymorphic. This polymorphism influences both blood plasma levels of drugs metabolized by CYP2C19 but also treatment outcome [29-32]. Like
CYP2D6, CYP2C19 has a broad substrate specificity and is involved in the metabolism of many different classes of psychotropic drugs, including selective serotonin reuptake inhibitors e.g. sertraline $[33,34]$ and citalopram [35,36], tricyclic antidepressants like amitriptyline [37] and clomipramine [38], and the monoamine oxidase inhibitor moclobemide [39]. CYP2C19 is furthermore involved in the metabolism of benzodiazepines e.g. diazepam [40] and the anticonvulsant drug mephenytoin [41,42] (Table 1).

Most studies investigating the effects of CYP2C19 polymorphism have been focused on the impact of drug plasma levels and related issues and therefore relatively little is known regarding endogenous effects of the CYP2C19 genotypes without drug challenge. However, some studies have suggested that $C Y P 2 C 19$ polymorphism also could play a role in predicting personality traits and depressive symptoms [43-45]. The suggested effect of CYP2C19 polymorphism on personality traits and depressive symptoms proposes that CYP2C19 is involved in the metabolism of endogenous substrates as well.

\section{Endogenous substrates}

Indeed, relatively few studies have investigated if CYP2C19 could be involved in the metabolism of endogenous compounds and due to its broad substrate specificity this is likely. In vitro studies performed in human liver microsomes have suggested $\mathrm{CYP} 2 \mathrm{C} 19$ to be involved in the metabolism of steroid hormones. CYP2C19 is shown to effectively catalyze the $17 \beta$-hydroxy dehydrogenation of estradiol into estrone [46] and furthermore to contribute to the formation of the estrone metabolite 16a-OH-estrone [47]. CYP2C19 has been suggested to metabolize progesterone into mainly $21-\mathrm{OH}$-progesterone but also to some extent 16a-OH-progesterone [48]. Besides being involved in the metabolism of estradiol and progesterone, CYP2C19 has also been shown to oxidize testosterone into mainly androstenedione, but also to a lesser extent, $6 \beta-, 16 \beta$-, and $2 \beta-\mathrm{OH}$-testosterone [48]. In conclusion, several studies show that CYP2C19 can metabolize different steroid hormones. However, effects connecting CYP2C19 polymorphism with hormone levels have so far not been investigated in vivo.

Most of these steroid hormones are known to be active and also synthesized within the CNS. Their functions are diverse and important for normal brain development and for postnatal brain maturation and plasticity [49-51]. Thus, there might be a role for CYP2C19 in the metabolism of CNS localized steroid hormones.

Besides steroids, CYP2C19 has been suggested to be involved in the metabolism of several different polyunsaturated fatty acids e.g. arachidonic acid, eicosapentaenoic acid, and docosahexaenoic acid $[52,53]$. Some studies have also proposed that CYP2C19 is important in the metabolism of the exogenous cannabinoid cannabidiol, thus suggesting that other endogenous cannabinoids could be potential substrates as well $[54,55]$. However this area of research need to be extended and confirmed before any firm conclusions can be drawn. Nevertheless the proposed substrates are highly relevant and the CYP2C19 dependent metabolism of these might possibly explain the associations seen between CYP2C19 polymorphism and human phenotypes as further emphasized below.

\section{Psychopathology and behavior}

The first studies on associations between CYP2C19 polymorphism and human phenotypes, without a drug challenge, investigated personality traits using the Temperament and Character Inventory (TCI) $[43,44]$. It was initially suggested, in a cohort of healthy Japanese, that CYP2C19 homozygous extensive metabolizers had a lower 
Citation: Persson A, Ingelman-Sundberg M (2014) Pharmacogenomics of Cytochrome P450 Dependent Metabolism of Endogenous Compounds: Implications for Behavior, Psychopathology and Treatment. J Pharmacogenomics Pharmacoproteomics 5: 127. doi:10.4172/21530645.1000127

score in harm avoidance (HA) compared to heterozygous extensive metabolizers and poor metabolizers [44]. This report proposes that higher CYP2C19 enzymatic activity is associated with a more carefree, outgoing, and optimistic personality. Other studies have furthermore shown that high scores in HA are strongly associated with depression and can also predict MDD [56-58].

Another study, also investigating healthy Japanese subjects, found that female CYP2C19 poor metabolizers scored significantly lower on the dimensions reward dependence, cooperativeness, and selftranscendence, compared to extensive metabolizers. Individuals with low scores in cooperativeness are more socially intolerant, unhelpful, and opportunistic [43] and has also been connected to a current state of depression [56]. Individuals with low scores in reward dependence are on the other hand more cold, practical, and withdrawn and low scores in self-transcendence are associated with an impatient, unimaginative, and proud personality [43].

The results from these two studies are rather inconclusive, but do however reveal some common aspects since CYP2C19 poor metabolizers displayed high scores in HA and low scores in cooperativeness, previously shown to associate with depression. However, the observed gender differences and low number of participants encourages for these studies to be reproduced in larger cohorts and also in other ethnic groups.

Apart from being connected to personality traits CYP2C19 polymorphism has also been associated with depressive symptoms. Subjects from the Swedish twin registry were assessed using the center for epidemiologic studies depression (CES-D) scale. The CES-D scale measures depressive symptoms and consists of four subscales that together form the total score (T1) with higher scores indicating higher levels of depressive symptoms during the last week [59]. This study suggests that poor metabolizers have lower depressive symptoms based on their significantly lower T1 scores, and lower scores on the subscales depressed mood, and psychomotor retardation and somatic complaints, compared to extensive metabolizers [45].

\section{Brain expression of CYP2C19}

Expression of CYP2C19 in humans has long been thought to be restricted to the liver and small intestine [60-62]. Recent preliminary studies of human fetal brain samples did however show relatively high cortical expression levels of CYP2C19, around $0.5 \%$ of that seen in adult liver. Transgenic mice for the human $C Y P 2 C 19$ gene also displayed

\section{A. Developmental brain expression of CYP2C19}

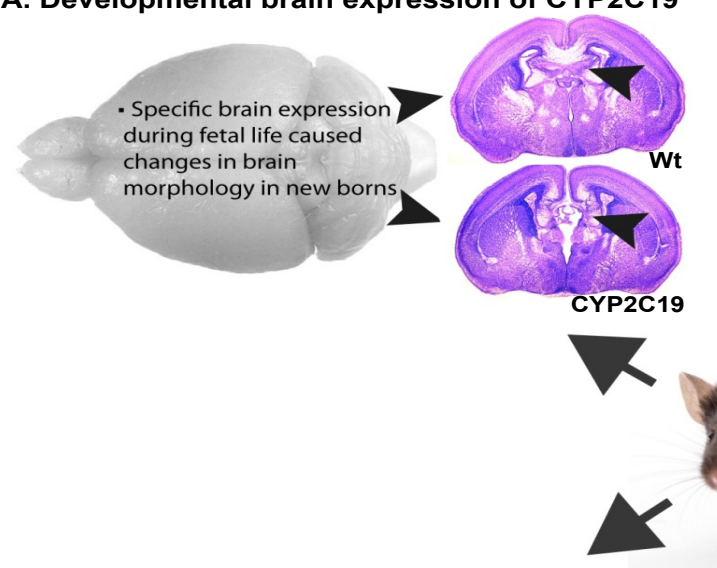

C. Increased stress sensitivity in CYP2C19 trangenic mice

\section{B. Anxiety-like behavior in CYP2C19 transgenic mice}

- Adult mice spent less time in the light compartment when exposed to the light-dark box

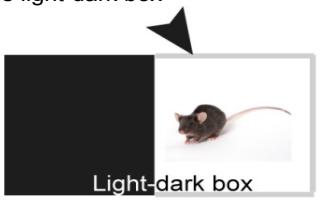

- Increased reactivity to novel environment:
- increased mobility in the open-field test
- Increased reactivity to short term stressor:
-reduced immobility in the tail-suspension tes
D. Altered hippocampal integrity in CYP2C19 trangenic mice

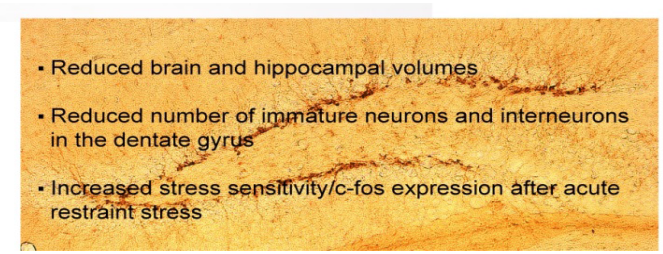

Figure 1: Phenotypes described for the human CYP2C19 transgenic mouse.

A. CYP2C19 mRNA expression was unexpectedly seen specifically in the brain during embryonic and fetal development in the CYP2C19 transgenic mouse. Brain CYP2C19 mRNA expression peaked at embryonic day 18, with a 6-fold higher expression in brain compared to liver but the expression silenced after birth. Preliminary data indicated that this brain expression of CYP2C19 occurs during fetal development of human brain as well. The morphological brain phenotype at postnatal day 0 in mice homozygous for the genetic insert (CYP2C19) compared to a Wt brain is presented. The CYP2C19 homozygous mice displayed an extensive morphological phenotype with complete callosal agenesis and a less developed and smaller hippocampal formation compared to Wt litter mates, changes indicated by arrows in the images.

B. Adult CYP2C19 transgenic mice displayed an increased anxiety-like behavior as measured by the light-dark box. They spent significantly less time in the light compartment compared to $\mathrm{Wt}$ litter mates, thus indicating an anxiogenic-like phenotype.

C. Adult CYP2C19 transgenic mice displayed an increased reactivity to stressful situations as displayed by their behavior in the tail-suspension test and in the open-field. They had an increased total distance travelled in the open-field compared to Wt controls and a significant reduction in immobility time was recorded in adult transgenic mice in the tail-suspension test.

D. Adult CYP2C19 transgenic mice showed a smaller brain and hippocampal volumes as measured by magnetic resonance imaging. Furthermore was the neuron population within the hippocampal formation severely affected with e.g. reduced number of immature neurons. In response to acute stress an increased neuronal activation (increased c-fos expression) was observed in the hippocampus of the transgenic mice thus indicating an altered stress response of the hippocampus in these mice. All data are adapted from [62]. 
Citation: Persson A, Ingelman-Sundberg M (2014) Pharmacogenomics of Cytochrome P450 Dependent Metabolism of Endogenous Compounds: Implications for Behavior, Psychopathology and Treatment. J Pharmacogenomics Pharmacoproteomics 5: 127. doi:10.4172/21530645.1000127

Page 4 of 6

\begin{tabular}{|c|c|c|c|}
\hline \multicolumn{2}{|c|}{ CYP2C19 } & \multicolumn{2}{|r|}{ CYP2D6 } \\
\hline UMs & PMs & UMs & PMs \\
\hline $\begin{array}{l}\text { In transgenic mice disturbance of } \\
\text { brain development including smaller } \\
\text { hippocampus }\end{array}$ & Decreased depressed mode & Higher suicidal risk & Higher risk for Parkinson's disease \\
\hline \multirow[t]{3}{*}{$\begin{array}{c}\text { In transgenic mice increased anxiety and } \\
\text { stress sensitivity }\end{array}$} & Higher score in harm avoidance & Increased suicidal behavior & $\begin{array}{l}\text { Higher impulsivity-related traits and more } \\
\text { anxiety prone }\end{array}$ \\
\hline & Lower score in cooperativeness & $\begin{array}{l}\text { Higher perfusion rates in thalamus and } \\
\text { hippocampus }\end{array}$ & Better capacity to vigilance and alertness \\
\hline & & & Perform better in spatial memory tasks \\
\hline
\end{tabular}

Table 2: Phenotypes described among subjects being poor metabolizers (PMs) or ultrarapid metabolizers (UMs) for CYP2C19 and CYP2D6 ( For further explanations see text).

specific brain expression of CYP2C19 during fetal life that is completely silenced after birth [63]. This suggests that CYP2C19 expression occurs as a peak in the CNS during fetal life and might then exert endogenous functions of importance for the development of the brain.

\section{CYP2C19 transgenic mouse model}

The transgenic mouse model for the human CYP2C19 gene displays some interesting phenotypes. High expression of the enzyme is lethal, with pups dying only a few days after birth. These mice display complete callosal agenesis and a severely underdeveloped hippocampus. Mice with fewer copies of the insert, possibly more closely resembling the expression seen in human rapid metabolizers, displayed no obvious neonatal disturbances of brain morphology. These mice did however show a behavioral phenotype in adult life, with increased stress sensitivity and increased anxiety-like behavior, as described in Figure 1 [63]. Stressful life events and stress sensitivity are major risk factors for psychiatric disease making this model highly interesting for investigating systems that are involved in regulating the stress response [64,65]. The CYP2C19 transgenic mice furthermore showed a hippocampal phenotype as adults, with a smaller and more stress sensitive hippocampal formation that furthermore contained a drastically reduced number of immature (double-cortin positive) neurons. The hippocampal formation has many critical functions including emotional processing, stress regulation, but also in learning tasks and memory formation [66-69]. Furthermore, the maturation and formation of new neurons within the hippocampus has been shown to be critical for normal hippocampal function [70,71] and the disturbances seen in the mouse model could be the explanation for the displayed smaller hippocampus. Reduced hippocampal volumes are commonly observed in several neuropsychiatric disorders including post-traumatic stress disorder [72], schizophrenia [73,74], and major depressive disorder $[75,76]$.

So even though it is likely that CYP2C19 enzymatic activity affects fetal brain development, a hippocampal and behavioral phenotype does not fully develop until young adulthood in the transgenic mice, similar to major depressive disorder and other neuropsychiatric disorders in humans were the manifestation generally occurs at this age $[77,78]$. A role of CYP2C19 in the metabolism of endogenous substances during brain development seems to be a likely explanation for the phenotypes observed in the transgenic mouse model but the identities of these substances remain to be discovered. The CYP2C19 transgenic mouse model indeed suggests that this enzyme is involved in the transformation of endogenous substrates involved in important brain developmental processes. These data are interesting and in line with the previously described link between the CYP2C19 polymorphism and depressive symptoms. One can speculate that the CYP2C19 phenotypes poor and rapid metabolizers have dissimilarities in their brain functions due to the presence of different levels of CYP2C19 during human brain development. Studies focused on this aspect in the developing human brain would be of severe interest in the future.

\section{Conclusions}

Psychotropic drug metabolizing enzymes, including cytochrome P450s, are present in the brain $[79,80]$ where they not only could contribute to local drug metabolism but also affect local biochemical homeostasis. CYPs, especially CYP2D6 and CYP2C19, are suggested to be involved in the transformation and metabolism of many endogenous substances including neurotransmitters and neurosteroids. Liver and brain levels of CYPs are highly dependent on genetic polymorphism which causes interindividual differences in drug levels and response. However, interindividual differences in local brain expression of these enzymes might also explain the reported associations between genetic polymorphism of e.g. CYP2D6 and CYP2C19 and personality traits, affective behaviour, and vulnerability to neuropsychiatric disorders as summarized in Table 2. This might raise some ethical issues with regard to the genetic tests recommended to determine treatment outcome and dose adjustments of many drugs metabolized by theses enzymes. However at the present stage such links are still not evidently shown and more research is needed before we can conclude that this would constitute an issue.

\section{Acknowledgement}

The research in the authors' laboratory is supported by grants from The Swedish Research Council, The Swedish Cancer Foundation and from EU-FP7.

\section{References}

1. Ingelman-Sundberg M, Sim SC, Gomez A, Rodriguez-Antona C (2007) Influence of cytochrome P450 polymorphisms on drug therapies: pharmacogenetic pharmacoepigenetic and clinical aspects. PharmacolTher 116: 496-526.

2. Zanger UM, Schwab M (2013) Cytochrome P450 enzymes in drug metabolism regulation of gene expression, enzyme activities, and impact of genetic variation. PharmacolTher 138: 103-141.

3. Yu AM,Fukamachi K, Krausz KW, Cheung C, Gonzalez FJ (2005) Potential role for human cytochrome P450 3A4 in estradiol homeostasis. Endocrinology 146: 2911-2919.

4. Miksys S, Tyndale RF (2013) Cytochrome P450-mediated drug metabolism in the brain. J Psychiatry Neurosci 38: 152-163.

5. Sim SC,Kacevska M, Ingelman-Sundberg M (2013) Pharmacogenomics of drug-metabolizing enzymes: a recent update on clinical implications and endogenous effects. Pharmacogenomics J 13: 1-11.

6. Ingelman-Sundberg M (2005) Genetic polymorphisms of cytochrome P450 2D6 (CYP2D6): clinical consequences, evolutionary aspects and functional diversity. Pharmacogenomics J 5: 6-13.

7. Siegle I, Fritz P, Eckhardt K, Zanger UM, Eichelbaum M (2001) Cellular localization and regional distribution of CYP2D 6 mRNA and protein expression in human brain. Pharmacogenetics 11: 237-245. 
Citation: Persson A, Ingelman-Sundberg M (2014) Pharmacogenomics of Cytochrome P450 Dependent Metabolism of Endogenous Compounds: Implications for Behavior, Psychopathology and Treatment. J Pharmacogenomics Pharmacoproteomics 5: 127. doi:10.4172/21530645.1000127

8. Dutheil F,Dauchy S, Diry M, Sazdovitch V, Cloarec O, et al. (2009) Xenobioticmetabolizing enzymes and transporters in the normal human brain: regional and cellular mapping as a basis for putative roles in cerebral function. Drug MetabDispos 37: 1528-1538.

9. Yu AM, Idle JR, Herraiz T, Küpfer A, Gonzalez FJ (2003) Screening for endogenous substrates reveals that CYP2D6 is a 5-methoxyindolethylamine O-demethylase. Pharmacogenetics 13: 307-319.

10. Hiroi T,Imaoka S, Funae Y (1998) Dopamine formation from tyramine by CYP2D6. BiochemBiophys Res Commun 249: 838-843.

11. Kishimoto W,Hiroi T, Shiraishi M, Osada M, Imaoka S, et al. (2004) Cytochrome P450 2D catalyze steroid 21-hydroxylation in the brain. Endocrinology 145 699-705.

12. Niwa T, Okada K, Hiroi T, Imaoka S, Narimatsu S, et al. (2008) Effect of psychotropic drugs on the 21-hydroxylation of neurosteroids, progesterone and allopregnanolone, catalyzed by rat CYP2D4 and human CYP2D6 in the brain Biol Pharm Bull 31: 348-351.

13. Cheng J, Zhen Y, Miksys S, BeyoÄŸlu D, Krausz KW, et al. (2013) Potential role of CYP2D6 in the central nervous system. Xenobiotica 43: 973-984.

14. Hiroi T,Kishimoto W, Chow T, Imaoka S, Igarashi T, et al. (2001) Progesterone oxidation by cytochrome P450 2D isoforms in the brain. Endocrinology 142 3901-3908.

15. Niwa T,Yabusaki Y, Honma K, Matsuo N, Tatsuta K, et al. (1998) Contribution of human hepatic cytochrome $\mathrm{P} 450$ isoforms to regioselective hydroxylation of steroid hormones. Xenobiotica 28: 539-547.

16. Snider NT,Sikora MJ, Sridar C, Feuerstein TJ, Rae JM, et al. (2008) The endocannabinoidanandamide is a substrate for the human polymorphic cytochrome P450 2D6. J PharmacolExpTher 327: 538-545.

17. Bertilsson L, Alm C, De Las Carreras C, Widen J, Edman G, et al. (1989) Debrisoquine hydroxylation polymorphism and personality. Lancet 1: 555.

18. Roberts RL,Luty SE, Mulder RT, Joyce PR, Kennedy MA (2004) Association between cytochrome P450 2D6 genotype and harm avoidance. Am J Med Genet B Neuropsychiatr Genet 127B: 90-93.

19. Llerena A,Edman G, Cobaleda J, Benítez J, Schalling D, et al. (1993) Relationship between personality and debrisoquine hydroxylation capacity. Suggestion of an endogenous neuroactive substrate or product of the cytochrome P4502D6. ActaPsychiatrScand 87: 23-28.

20. González I,Peñas-Lledó EM, Pérez B, Dorado P, Alvarez M, et al. (2008) Relation between CYP2D6 phenotype and genotype and personality in healthy volunteers. Pharmacogenomics 9: 833-840.

21. Zackrisson AL,Lindblom B, Ahlner J (2010) High frequency of occurrence of CYP2D6 gene duplication/multiduplication indicating ultrarapid metabolism among suicide cases. ClinPharmacolTher 88: 354-359.

22. Stingl JC, Viviani $\mathrm{R}$ (2011) CYP2D6 in the brain: impact on suicidality ClinPharmacolTher 89: 352-353.

23. Peñas-Lledó EM, Dorado P, Agüera Z, Gratacós M, Estivill X, et al. (2011) High risk of lifetime history of suicide attempts among CYP2D6 ultrarapid metabolizers with eating disorders. Mol Psychiatry 16: 691-692.

24. Kirchheiner J,Seeringer A, Godoy AL, Ohmle B, Maier C, et al. (2011) CYP2D6 in the brain: genotype effects on resting brain perfusion. Mol Psychiatry 16: 237, 333-341.

25. Stingl JC,Esslinger C, Tost $H$, Bilek E, Kirsch P, et al. (2012) Genetic variation in CYP2D6 impacts neural activation during cognitive tasks in humans. Neuroimage 59: 2818-2823.

26. Lu Y,Peng Q,Zeng Z2, Wang J, Deng Y, et al. (2014) CYP2D6 phenotypes and Parkinson's disease risk: a meta-analysis. J NeurolSci 336: 161-168.

27. Peñas-LLedó EM, Dorado P, Pacheco R, González I, LLerena A (2009) Relation between CYP2D6 genotype, personality, neurocognition and overal psychopathology in healthy volunteers. Pharmacogenomics 10: 1111-1120.

28. Zanger UM,Turpeinen M, Klein K, Schwab M (2008) Functional pharmacogenetics/genomics of human cytochromes P450 involved in drug biotransformation. Anal BioanalChem 392: 1093-1108.

29. Schenk PW, van Vliet M, Mathot RA, van Gelder T, Vulto AG, et al. (2010) The CYP2C19*17 genotype is associated with lower imipramine plasma concentrations in a large group of depressed patients. Pharmacogenomics $J$ 10: $219-225$
30. Rudberg I,Mohebi B, Hermann M, Refsum H, Molden E (2008) Impact of the ultrarapid CYP2C19*17 allele on serum concentration of escitalopram in psychiatric patients. ClinPharmacolTher 83: 322-327.

31. Huezo-Diaz P,Perroud N, Spencer EP, Smith R, Sim S, et al. (2012) CYP2C19 genotype predicts steady state escitalopram concentration in GENDEP. Psychopharmacol 26: 398-407.

32. Mrazek DA,Biernacka JM, O'Kane DJ, Black JL, Cunningham JM, et al. (2011) CYP2C19 variation and citalopram response. Pharmacogenet Genomics 21 $1-9$

33. Xu ZH, Wang W, Zhao XJ, Huang SL, Zhu B, et al. (1999) Evidence for involvement of polymorphic CYP2C19 and 2C9 in the $\mathrm{N}$-demethylation of sertraline in human liver microsomes. $\mathrm{Br} \mathrm{J}$ ClinPharmacol 48: 416-423.

34. Wang JH, Liu ZQ, Wang W, Chen XP, Shu Y, et al. (2001) Pharmacokinetics of sertraline in relation to genetic polymorphism of CYP2C19. ClinPharmacolTher 70: 42-47.

35. Herrlin K Yasui-Furukori N, Tybring G, Widén J, Gustafsson LL, et al. (2003) Metabolism of citalopram enantiomers in CYP2C19/CYP2D6 phenotyped panels of healthy Swedes. Br J ClinPharmacol 56: 415-421.

36. Yu BN, Chen GL, He N, Ouyang DS, Chen XP, et al. (2003) Pharmacokinetics of citalopram in relation to genetic polymorphism of CYP2C19. Drug MetabDispos 31: $1255-1259$.

37. Shimoda K,Someya T, Yokono A, Morita S, Hirokane G, et al. (2002) The impact of CYP2C19 and CYP2D6 genotypes on metabolism of amitriptyline in Japanese psychiatric patients. J ClinPsychopharmacol 22: 371-378.

38. Yokono A, Morita S, Someya T, Hirokane G, Okawa M, et al. (2001) The effect of CYP2C19 and CYP2D6 genotypes on the metabolism of clomipramine in Japanese psychiatric patients. J ClinPsychopharmacol 21: 549-555.

39. Yu KS, Yim DS, Cho JY, Park SS, Park JY, et al. (2001) Effect of omeprazole on the pharmacokinetics of moclobemide according to the genetic polymorphism of CYP2C19. ClinPharmacolTher 69: 266-273.

40. Fukasawa T, Suzuki A, Otani K (2007) Effects of genetic polymorphism of cytochrome P450 enzymes on the pharmacokinetics of benzodiazepines. $J$ Clin Pharm Ther 32: 333-341.

41. Laine K, Tybring G, Bertilsson $L$ (2000) No sex-related differences but significan inhibition by oral contraceptives of CYP2C19 activity as measured by the probe drugs mephenytoin and omeprazole in healthy Swedish white subjects. ClinPharmacolTher 68: 151-159.

42. Tamminga WJ,Wemer J, Oosterhuis B, Wieling J, Touw DJ, et al. (2001) Mephenytoin as a probe for CYP2C19 phenotyping:effect of sample storage, intra-individual reproducibility and occurrence of adverse events. $\mathrm{Br} J$ ClinPharmacol 51: 471-474.

43. Ishii G, Suzuki A, Oshino S, Shiraishi H, Otani K (2007) CYP2C19 polymorphism affects personality traits of Japanese females. NeurosciLett 411: 77-80.

44. Yasui-Furukori N,Kaneda A, Iwashima K, Saito M, Nakagami T, et al. (2007) Association between cytochrome P450 (CYP) 2C19 polymorphisms and harm avoidance in Japanese. Am J Med Genet B Neuropsychiatr Genet 144B: 724 727.

45. Sim SC,Nordin L, Andersson TM, Virding S, Olsson M, et al. (2010) Association between CYP2C19 polymorphism and depressive symptoms. Am J Med Genet B Neuropsychiatr Genet 153B: 1160-1166

46. Cheng ZN,Shu Y, Liu ZQ, Wang LS, Ou-Yang DS, et al. (2001) Role of cytochrome P450 in estradiol metabolism in vitro. ActaPharmacol Sin 22: 148 154

47. Cribb AE, Knight MJ, Dryer D, Guernsey J, Hender K, et al. (2006) Role of polymorphic human cytochrome P450 enzymes in estrone oxidation. Cancer Epidemiol Biomarkers Prev 15: 551-558.

48. Yamazaki H, Shimada $\mathrm{T}(1997)$ Progesterone and testosterone hydroxylation by cytochromes P450 2C19, 2C9, and 3A4 in human liver microsomes. Arch BiochemBiophys 346: 161-169.

49. Peper JS, van den Heuvel MP, Mandl RC, Hulshoff Pol HE, van Honk J (2011) Sex steroids and connectivity in the human brain: a review of neuroimaging studies. Psychoneuroendocrinology 36: 1101-1113.

50. Westberg L, Eriksson E (2008) Sex steroid-related candidate genes in psychiatric disorders. J Psychiatry Neurosci 33: 319-330. 
Citation: Persson A, Ingelman-Sundberg M (2014) Pharmacogenomics of Cytochrome P450 Dependent Metabolism of Endogenous Compounds: Implications for Behavior, Psychopathology and Treatment. J Pharmacogenomics Pharmacoproteomics 5: 127. doi:10.4172/21530645.1000127

51. Brown GR, Spencer KA (2013) Steroid hormones, stress and the adolescent brain: a comparative perspective. Neuroscience 249: 115-128.

52. Fer M,Dréano Y, Lucas D, Corcos L, Salaün JP, et al. (2008) Metabolism of eicosapentaenoic and docosahexaenoic acids by recombinant human cytochromes P450. Arch BiochemBiophys 471: 116-125.

53. Yao HT, Chang YW, Lan SJ, Chen CT, Hsu JT, et al. (2006) The inhibitory effect of polyunsaturated fatty acids on human CYP enzymes. Life Sci 79: 2432-2440.

54. Jiang R,Yamaori S, Takeda S, Yamamoto I, Watanabe K (2011) Identification of cytochrome P450 enzymes responsible for metabolism of cannabidiol by human liver microsomes. Life Sci 89: 165-170.

55. Jiang R,Yamaori S, Okamoto Y, Yamamoto I, Watanabe K (2013) Cannabidiol is a potent inhibitor of the catalytic activity of cytochrome P450 2C19. Drug MetabPharmacokinet 28: 332-338.

56. Farmer A,Mahmood A, Redman K, Harris T, Sadler S, et al. (2003) A sib-pair study of the Temperament and Character Inventory scales in major depression. Arch Gen Psychiatry 60: 490-496

57. Cloninger CR,Svrakic DM, Przybeck TR (2006) Can personality assessment predict future depression? A twelve-month follow-up of 631 subjects. J Affect Disord 92: 35-44

58. Farmer RF, Seeley JR (2009) Temperament and character predictors of depressed mood over a 4-year interval. Depress Anxiety 26: 371-381.

59. Gatz M, Johansson B, Pedersen N, Berg S, Reynolds C (1993) A cross-national self-report measure of depressive symptomatology. IntPsychogeriatr 5: 147156.

60. Klose TS,Blaisdell JA, Goldstein JA (1999) Gene structure of CYP2C8 and extrahepatic distribution of the human CYP2Cs. J BiochemMolToxicol 13: 289295.

61. Läpple F, von Richter O, Fromm MF, Richter T, Thon KP, et al. (2003) Differential expression and function of CYP2C isoforms in human intestine and liver. Pharmacogenetics 13: 565-575.

62. Wu M, Chen S, Wu X (2006) Differences in cytochrome P450 2C19 (CYP2C19) expression in adjacent normal and tumor tissues in Chinese cancer patients. Med SciMonit 12: BR174-178.

63. Persson A,Sim SC, Virding S, Onishchenko N, Schulte G, et al. (2013) Decreased hippocampal volume and increased anxiety in a transgenic mouse model expressing the human CYP2C19 gene. MolPsychiatry .

64. Pietrek C, Elbert T, Weierstall R, Müller O, Rockstroh B (2013) Childhood adversities in relation to psychiatric disorders. Psychiatry Res 206: 103-110.

65. Fisher HL, Cohen-Woods S, Hosang GM, Uher R, Powell-Smith G, et al. (2012) Stressful life events and the serotonin transporter gene (5-HTT) in recurrent clinical depression. J Affect Disord 136: 189-193.
66. Kheirbek MA, Drew LJ, Burghardt NS, Costantini DO, Tannenholz L, et al. (2013) Differential control of learning and anxiety along the dorsoventral axis of the dentate gyrus. Neuron 77: 955-968.

67. Snyder JS,Soumier A, Brewer M, Pickel J, Cameron HA (2011) Adult hippocampal neurogenesis buffers stress responses and depressive behaviour. Nature 476: 458-461.

68. Lewis S (2012) Learning and memory: Hippocampus plays multiple choice. Nat Rev Neurosci 13: 600

69. Femenía T, Gómez-Galán M, Lindskog M, Magara S (2012) Dysfunctional hippocampal activity affects emotion and cognition in mood disorders. Brain Res 1476: 58-70.

70. Snyder JS, Cameron HA (2012) Could adult hippocampal neurogenesis be relevant for human behavior? Behav Brain Res 227: 384-390.

71. Song J, Christian KM, Ming GL, Song H (2012) Modification of hippocampa circuitry by adult neurogenesis. DevNeurobiol 72: 1032-1043.

72. Woon FL, Hedges DW (2008) Hippocampal and amygdala volumes in children and adults with childhood maltreatment-related posttraumatic stress disorder: a meta-analysis. Hippocampus 18: 729-736.

73. Kheirbek MA, Klemenhagen KC, Sahay A, Hen R (2012) Neurogenesis and generalization: a new approach to stratify and treat anxiety disorders. Nat Neurosci 15: 1613-1620.

74. Adriano F,Caltagirone C, Spalletta G (2012) Hippocampal volume reduction in first-episode and chronic schizophrenia: a review and meta-analysis. Neuroscientist 18: 180-200

75. Campbell S, Marriott M, Nahmias C, MacQueen GM (2004) Lower hippocampal volume in patients suffering from depression: a meta-analysis. Am J Psychiatry 161: 598-607.

76. Videbech P,Ravnkilde B (2004) Hippocampal volume and depression: a metaanalysis of MRI studies. Am J Psychiatry 161: 1957-1966.

77. Klein DN, Glenn CR, Kosty DB, Seeley JR, Rohde P, et al. (2013) Predictors of first lifetime onset of major depressive disorder in young adulthood. J AbnormPsychol 122: 1-6.

78. Kessler RC, Berglund P, Demler O, Jin R, Merikangas KR, et al. (2005) Lifetime prevalence and age-of-onset distributions of DSM-IV disorders in the National Comorbidity Survey Replication. Arch Gen Psychiatry 62: 593-602.

79. Stingl JC,Brockmöller J, Viviani R (2013) Genetic variability of drugmetabolizing enzymes: the dual impact on psychiatric therapy and regulation of brain function. Mol Psychiatry 18: 273-287.

80. Ferguson CS, Tyndale RF (2011) Cytochrome P450 enzymes in the brain emerging evidence of biological significance. Trends PharmacolSci 32: 708714 